\title{
Early onset myotonic dystrophy in association with polyneuropathy
}

\author{
KANNEN PARAMESH ${ }^{1}$, BERNARD H. SMITH, AND K. KALYANARAMAN \\ From the Department of Neurology, Edward J. Meyer Memorial Hospital, \\ State University of New York at Buffalo, Buffalo, New York, USA
}

SYNOPSIS A patient with early onset myotonic dystrophy, with associated neuropathy and epilepsy, is presented. It is postulated that his disorder was inherited through a recessive, pleomorphic gene. His differential diagnosis is discussed and the literature reviewed. The clinical variability of myotonic dystrophy is stressed and the diagnostic difficulties encountered in the younger age group.

The occurrence of myotonic dystrophy in children as compared with adults is relatively uncommon. There have been reports of its incidence between the ages 6 and 14 years by Maas and Patterson (1943). However, it was Vanier (1960), Dodge et al. (1965), and Pruzanski (1966) who put the subject into proper perspective, recognizing the atypical nature of the disease in children. They described, besides the classical type, the dysembryoplasic and dysphagic types (Dodge et al., 1965; Pruzanski, 1966), and divided their patients into three groups according to the clinical manifestation. Watters and Williams (1967) added a fourth group.

The features considered to be characteristic in adults, such as ptosis, cataracts, baldness, endocrine abnormalities, and percussion myotonia, are seldom seen in the younger age group (Watters and Williams, 1967). Found instead are congenital anomalies such as high arched palate and skeletal abnormalities like talipes equinovarus and kyphoscoliosis (Aberfield et al., 1965; Pearson et al., 1967).

Recently there have been reports of evidence of neuropathy associated with myotonic dystrophy (McComas et al., 1971; Caccia et al., 1972; Kalyanaraman et al., 1973).

The purpose of this paper is to stress the pleomorphism of myotonic dystrophy in the

\footnotetext{
1 Address for reprint requests: Dr Kannen Paramesh, Neurology Service (180), VA Wadsworth Hospital Center, Wilshire and Sawtelle Blvds. Los Angeles, CA 90073, U.S.A. (Accepted 15 April 1975.)
}

younger age group and to report associated neuropathy.

\section{CASE REPORT}

K. B. was an 18 year old male who complained of progressive weakness in all limbs. His parents were unrelated and his prenatal and postnatal histories were unremarkable. His motor milestones were delayed: he was late in sitting up and in being able to lift his head off the bed; he never crawled and did not walk till the age of 2 years. He began to talk 'at the usual time'. His mother had early noted occasional twitching movements of the left eyelids.

He had been seen by a neurologist at the age of 4 years: at that time episodes of left facial twitching were reported; there was universal motor weakness, particularly involving the neck flexors; and there was generalized hypotonia and areflexia. The face was 'hatchet shaped' and there was delayed relaxation of the handgrip.

At the age of 10 years he had a grand mal seizure preceded by dizziness and 'twinkling lights' in the left visual field, and was started on phenobarbitone and diphenylhydantoin.

There was no family history of similar difficulties; both his parents were in good health as was one younger sister.

He was a pleasant adolescent of normal intelligence. The face was long and thin; the head scaphocephalic; the neck thin and swan-like, with extreme wasting of the sternocleidomastoid muscles (Fig. 1) and marked weakness of the flexor muscles of the neck so that the head could not be lifted against gravity; the palate was high-arched and the teeth malaligned. The cardiac, respiratory, and gastro- 


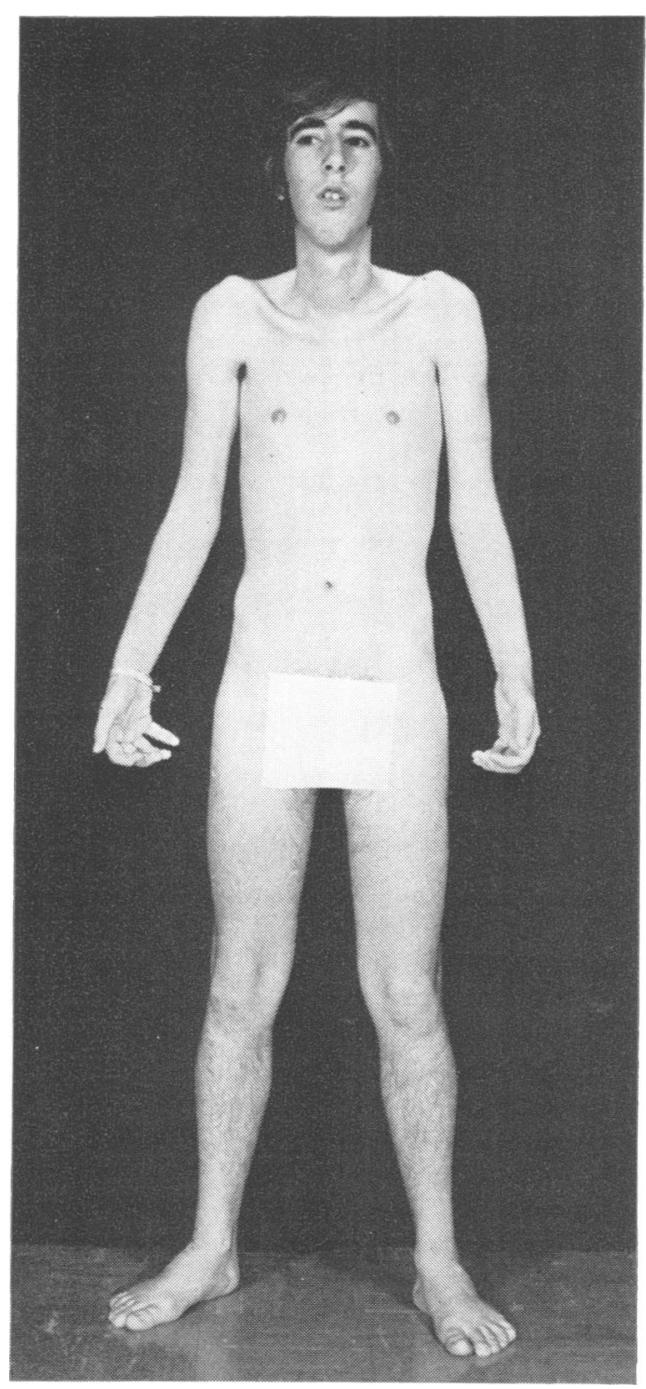

FIG. 1 K.B.: showing extreme wasting of sternomastoids, proximal, and distal muscles in the upper extremities.

intestinal systems were unremarkable and the genitalia normal. The orbicularis oculi and lower facial muscles were weak bilaterally. Bilateral foot drop was obvious when he walked. In the upper limbs there was severe proximal and distal muscular atrophy, and the sternal heads of the pectoralis major muscles were absent. There was universal weakness in the lower limbs, with particular involvement of the extensors, flexors, and evertors of the ankles. The calves showed pseudohypertrophy. There was generalized hypotonia and areflexia. No sensory changes were detected and sphincter function was intact.

Urinalysis, complete blood count, total plasma protein, plasma albumin-globulin ratio, immunoelectrophoresis, fasting blood sugar, serum aldolase, aspartate transaminase, alanine transaminase and lactate dehydrogenase levels were normal. Serum creatine phosphokinase was 343 I.U./l. Serum levels of phenobarbitone and diphenylhydantoin were normal. Radiographs of the skull, cervical spine, and chest were normal as were the EEG and brain scan. The electrocardiogram showed normal sinus rhythm. The spinal fluid protein was $0.89 \mathrm{~g} / \mathrm{l}$ and the sugar $38.9 \mathrm{mmol} / \mathrm{l}(70 \mathrm{mg} / \mathrm{dl})$.

Electromyography and nerve conduction studies were done under standardized conditions with a Teca Model TE-4 machine at a room temperature of $24^{\circ} \mathrm{C}$ with right forearm temperature being $34^{\circ} \mathrm{C}$ and the right leg temperature $32^{\circ} \mathrm{C}$. Maximal motor nerve conduction velocities were as follows: right median $39.2 \mathrm{~m} / \mathrm{s}$; right ulnar $40.2 \mathrm{~m} / \mathrm{s}$, right peroneal $32.6 \mathrm{~m} / \mathrm{s}$, right tibial $35.7 \mathrm{~m} / \mathrm{s}$. Orthodromic sensory conduction velocities were: right median (finger to wrist) $40 \mathrm{~m} / \mathrm{s}$, right median (finger to elbow) $43.4 \mathrm{~m} / \mathrm{s}$, right ulnar (finger to wrist) $33.3 \mathrm{~m} / \mathrm{s}$, right ulnar (finger to elbow) - no evoked potential could be obtained.

The following muscles were tested on the right side with a concentric needle electrode: peronei, tibialis anterior, gastrocnemius, opponens pollicis, abductor digiti minimi, and biceps. The peronei and biceps showed classic myotonic discharges with 'dive bomber' sound and bizarre high frequency (pseudomyotonic) discharges. The other muscles showed increased insertional irritability and positive sharp waves. The motor unit potentials were reduced in number on maximal contraction and motor unit potentials were polyphasic and prolonged (10-15 ms in duration). These findings indicated a neurogenic atrophy of muscles in addition to the myotonia.

Biopsy of the left gastrocnemius muscle was carried out under local anaesthesia; paraffin embedded sections were stained with haematoxylin and eosin, trichrome, and PTAH. Rapidly frozen sections were also studied histochemically with phosphorylase, myosin-ATPase and DNPH-diaphorase.

Histological features such as rounding and variation of diameter of muscle fibres, central nucleation, and occasional necrosis were prominently myopathic (Fig. 2). Ring fibres, sarcoplasmic masses, and nuclear chains were absent. Histochemical studies showed normal fibre type differentiation with a tendency of type I fibre hypotrophy. 


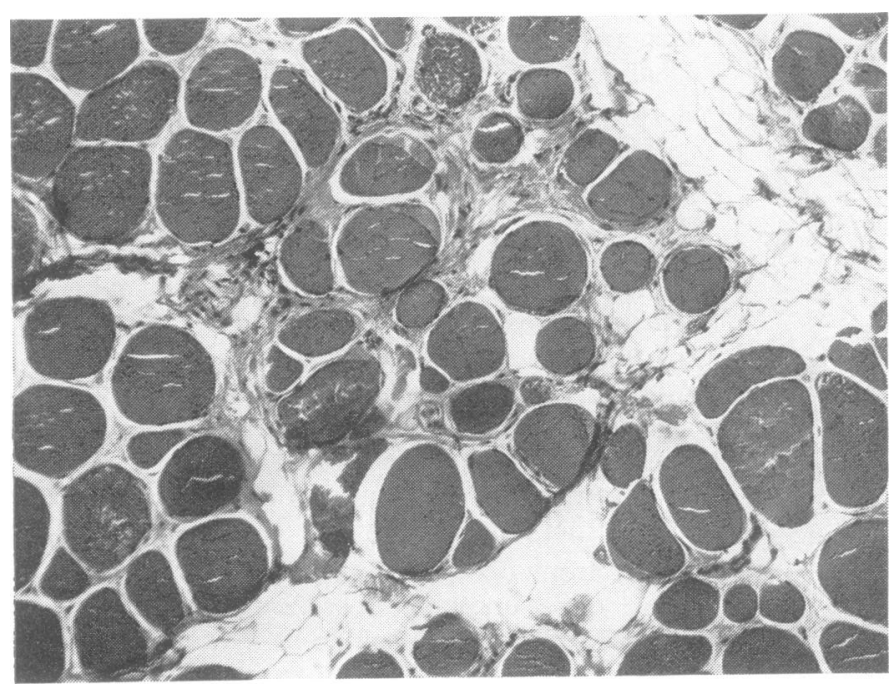

FIG. 2 Biopsy of left gastrocnemius: showing rounding and variation of muscle fibre size and areas of necrosis. $H$ and $E, \times 250$.

\section{DISCUSSION}

The clinical and laboratory data pointed to early onset myotonic dystrophy. The clinical features were classical: the delayed milestones, hypotonia, facial spasms, poor relaxation of handgrip, weakness and wasting of neck muscles, hatchetshaped face, and high-arched palate. The EMG and muscle biopsy confirmed the diagnosis. However, the EMG study raised some questions discussed below.

INHERITANCE The mode of inheritance of myotonic dystrophy is thought to be autosomal dominant (Tyler, 1954; Vanier, 1960; Caughey and Myrianthopoulos, 1963; Dodge et al., 1965; Pearson et al., 1967). In our case, the parents and sister were studied clinically and by EMG and were normal. The inheritance is therefore presumed to be recessive; or the case may have been sporadic.

The genes transmitting the early-onset and adult types of muscular dystrophy may be different (Carter and Bundy, 1972). The adult cases with neuropathy seen by us were sporadic (Kalyanaraman et al., 1973). It is therefore possible that myotonic dystrophy with neuropathy differs genetically from the classical type.

NEUROPATHIC FEATURES Engel (1971) postu- lated that the peripheral nerve has an 'inhibitory' influence on myoneural function and that the loss of this inhibitory influence is manifested as myotonia. McComas et al. (1971) were of the opinion that the changes in the muscle were the result of a primary neuropathy.

In the cases of myotonia associated with neuropathy studied by Caccia et al. (1972), there was conclusive EMG and histopathological evidence for neuropathy. The two cases of adult onset myotonic dystrophy reported by Kalyanaraman et al. (1973) showed evidence of neuropathy by EMG and muscle biopsy.

Our present patient had electromyographic evidence of neuropathy in the form of slowed motor conduction. In addition, the spinal fluid protein was elevated; an abnormality noted by Refsum et al. (1967) in nine of their 16 cases.

The question also arose whether the diphenylhydantoin he was taking for epilepsy could have been responsible for the neuropathy and the elevated spinal fluid protein. Rawson (1968) studied the spinal fluid in four patients with diphenylhydantoin intoxication: the protein was elevated in all, as was the serum level of the drug; and they all had clinical signs of cerebellar dysfunction. When, in these patients, the serum levels of the drug were lowered to the therapeutic range, the clinical signs cleared and the 
spinal fluid protein returned to normal. Our patient showed no clinical signs of diphenylhydantoin intoxication, and had normal serum levels of the drug. We do not think it likely, therefore, that diphenylhydantoin contributed to his neuropathy. Diphenylhydantoin, though used here for the control of seizures, has since been tried in the therapy of myotonia (Munsat, 1967). Hence it is possible that it may have masked clinical myotonia in our patient. The raised spinal fluid protein and the neuropathy also raised the question of Landry-GuillainBarré-Strohl syndrome with reactive myotonia (Worster-Drought and Sargent, 1952). This was unlikely in our case because of the history, clinical picture, and biopsy findings.

Multisystem involvement is known in myotonic dystrophy and there have been reports of associated hereditary neuropathy (Ziegler and Rogoff, 1956), as well as of Charcot-MarieTooth disease (Wald et al., 1962) and of Friedreich's ataxia (Chaco and Taustein, 1969). In all of these cases there was a strong family history. However, in our patient, the gene may have been recessive and pleomorphic, transmitting both the myotonic dystrophy and the neuropathy, without similar manifestations in other members of the family.

Epilepsy has not (as far as we are aware) been previously described as occurring in myotonic dystrophy, though non-specific changes in the EEG have been seen (Barwick et al., 1965; Watters and Williams, 1967). Central nervous system involvement in myotonic dystrophy usually takes the form of dementia and cerebral atrophy (Refsum et al., 1967). In our case the epilepsy may be coincidental.

In conclusion, we think our patient manifested early onset myotonic dystrophy with associated neuropathy.

\section{REFERENCES}

Aberfield, D. C. Hinterbuchner, L. P., and Schneider, M. (1965). Myotonia, dwarfism, diffuse bone disease and unusual ocular and facial abnormalities. (A new syndrome.) Brain, 88, 313-321.

Barwick, D. D., Osselton, J. W., and Walton, J. N. (1965). Electroencephalographic abnormalities in hereditary myopathy. Journal of Neurology, Neurosurgery, and Psychiatry, 28, 109-114.

Caccia, M. R., Negri, S., and Parvis, P. (1972). Myotonic dystrophy with neural involvement. Journal of Neurological Sciences, 16, 253-269.

Carter, C. O., and Bundy, S. (1972). Early onset of dystrophia myotonica. Lancet, 2, 336-337.

Caughey, J. E., and Myrianthopoulos, N. C. (1963). Dystrophia Myotonica and Related Disorders. Thomas: Springfield, Ill.

Chaco, J., and Taustein, I. (1969). Myotonia dystrophica and Friedreich's ataxia in one patient. European Neurology, 2, 123-126.

Dodge, P. R., Gamstrop, I., Byers, R. K., and Russell, P. (1965). Myotonic dystrophy in infancy and childhood. Pediatrics, 35, 3-19.

Engel, W. K. (1971). Myotonia-a different point of view. California Medicine, 114, 32-37.

Kalyanaraman, K., Smith, B. H., and Chadha, A. L. (1973). Evidence of neuropathy in myotonic muscular dystrophy. Bulletin of the Los Angeles Neurological Societies, 38, 188-196.

McComas, A. J., Sica, R. E. P., and Campbell, M. J. (1971). 'Sick' motorneurones; A unifying concept of muscle, disease. Lancet, 1, 321-325.

Maas, O., and Patterson, S. (1943). Genetic and familial aspects of dystrophia myotonia. Brain, 66, 55-86.

Munsat, T. L. (1967). Therapy of myotonia-A double-blind evaluation of diphenylhydantoin, procainamide and placebo. Neurology (Minneap.), 17, 359-367.

Pearson, C., Kar, N. C., Peter, J., Munsat, T., Fowler, W., and Coleman, R. (1967). Myotonic dystrophy; its variable clinical, histological and biochemical expressions. In Progress in Neurogenetics, vol. 1, pp. 199-218. Proceedings of the 2nd International Congress of Neurogenetics and Neuroophthalmology. International Congress, series no. 175. Excerpta Medica: Amsterdam.

Pruzanski, W. (1966). Variants of myotonic dystrophy in preadolescent life (The syndrome of myotonic dysembryoplasia). Brain, 89, 563-568.

Rawson, M. D. (1968). Diphenylhydantoin intoxication and CSF protein. Neurology (Minneap.), 18, 1009-1011.

Refsum, S., Lonnum, A., Sjaastad, D., and Engeset, A. (1967). Dystrophia myotonica. Neurology (Minneap.), 17, 345-348.

Tyler, F. H. (1954). The inheritance of neuromuscular disease. Research Publications of the Association for Research in Nervous and Mental Disease, 33, 283-292.

Vanier, T. M. (1960). Dystrophia myotonica in childhood. British Medical Journal, 2, 1284-1288.

Wald, I., Loesch, D., and Wochnick, D. (1962). Concerning the relationship between dystrophia myotonica and peroneal muscular atrophy. Psychiatria Clinica (Basel), 143, 392-397.

Watters, G. V., and Williams, T. (1967). Early onset myotonic dystrophy clinical and laboratory findings in five families and review of literature. Archives of Neurology (Chic.), 17, 137-152.

Worster-Drought, C., and Sargent, F. (1952). Muscular fasciculation and reactive myotonia in polyneuritis. Brain, 75, 595-600.

Ziegler, D. K., and Rogoff, J. (1956). Rare variant of myotonia atrophica - clinical and electromyographic study of a family. Brain, 79, 349-375. 